Teoría y
D E BAT E 
Annel Vázquez Anderson

\section{Democracia en México: transición hacia un corporativismo social'}

Para que los hombres se tornen o permanezcan civilizados, el arte de asociación debe desarrollarse y perfeccionarse entre ellos en la misma medida en que la igualdad de condiciones entre ellos crece. Alexis de Tocqueville
Así como las viejas democracias tienen el riesgo de convertirse en tiranías de la mayoría, los nuevos sistemas democráticos están constantemente en peligro de ser ingobernables. Las instituciones tradicionalmente democráticas como los partidos políticos y los parlamentos no han ayudado a eliminar o por lo menos a reducir esos riesgos. Éstos deben decidir pragmáticamente lo que la mayoría quiere o perderse en el objetivo ideal de responder a la confusa y contradictoria pluralidad. ¿Tenemos otras alternativas además de éstas? Philippe Schmitter nos dio en 1986 esperanzas con su propuesta

de corporativismo renovado como una forma alternativa de representación social. Este ensayo intenta ser una propuesta de diseño institucional y organizacional. Se proponen un modelo de corporativismo social y otro de sindicalismo para México.

Palabras clave: México, Corporativismo, democracia, sindicalismo y gobernabilidad

- Maestra en Ciencia Política por la New School de Nueva York y Profesora del Departamento de Estudios Políticos, Universidad de Guadalajara.

teannelo@hotmail.com
¿Es aún posible que la democracia sobreviva sin perder sus características básicas? Así como las viejas democracias corren el riesgo de convertirse en tiranías de la mayoría, los nuevos sistemas democráticos están constantemente en peligro de ser ingobernables. Peor aún, las instituciones tradicionalmente democráticas, como los partidos políticos y los parlamentos, no han ayudado a eliminar o, por lo menos, a reducir los riesgos. Les hemos delegado una complicada tarea: escuchar y responder a las demandas de cada grupo de la sociedad. Es así que ellos deben pragmáticamente decidir, a partir de lo que la

I. Este ensayo se elaboró a partir del trabajo que presenté para obtener el título de maestría y de dos artículos publicados en el suplemento político "La Brecha" del periódico El Occidental: "Los costos del cambio en México", y "El corporativismo liberal, una alternativa para el problema de gobernabilidad en la democracia".

Espiral, Estudios sobre Estado y Sociedad

Vol. X No. 29 ¿ Enero / Abril de 2004 
mayoría quiere, o perderse en la misión ideal de responder a la confusa y contradictoria pluralidad. ¿Tenemos otras alternativas además de éstas?

Philippe Schmitter renovó nuestras esperanzas en $1986^{2}$ (aunque algunos dirían, nuestros miedos) con su propuesta de un nuevo corporativismo (o, para usar su propio término, neocorporativismo) como forma alternativa de representación social. El corporativismo ha sido intensamente criticado al ser identificado como instrumento frecuente de sistemas autoritarios o hasta totalitarios. La discusión deviene interesante cuando Schmitter claramente diferencia su propuesta de aquel corporativismo asociado a sistemas no democráticos, llamando a este último corporativismo de Estado y, al suyo, corporativismo social.

A partir de la distinción de Schmitter podemos asumir, entonces, que el corporativismo mexicano ha sido de Estado. El corporativismo nació en México al tiempo en que el Partido Nacional Revolucionario (PNR) se convirtió en el Partido de la Revolución Mexicana (PRM). Es así que en nuestro país el corporativismo se asocia directamente con acciones populistas que sólo atienden a la legitimación de un régimen autoritario; acciones que dan lugar a clientelismos al convertir los distintos intereses de clase en instrumentos de control, subordinación y dominación. Aun con todo, el corporativismo tiene una misión y el mexicano sin duda la cumplió: la gobernabilidad y la estabilidad política. Sin embargo, nos encontramos ya en otro momento, un momento democrático, y este modelo corporativista no puede mantenerse, debe ser transformado.

Existen innumerables complicaciones para la realización de esta tarea. Se hizo alusión previamente a una de ellas: la idea generalizada sobre la incompatibilidad del corpora- 
tivismo y la democracia. Por ello, la sola sugerencia de otro tipo de corporativismo nace ya ilegítima. Por si esto no fuera suficiente, la globalización crea condiciones que hacen la formación de modelos corporativos extremadamente difícil. Las costumbres corporativas son percibidas como límites a la flexibilidad, al libre movimiento del mercado y a la posibilidad de innovación gubernamental. El espíritu neoliberal, además de leerse en el Tratado de Libre Comercio (TLC) también es percibido en la vida diaria. Una peligrosa contradicción aparece: por un lado, los viejos usos corporativos continúan siendo parte del pragmático accionismo del nuevo presidente y, por otro, la fuerte convicción neoliberal del presidente, aunada a la gran presión de los grandes negocios, resulta en planes gubernamentales que buscan debilitar la fuerza de la clase laboral. Como siempre, son los trabajadores los más afectados.

No podemos considerarnos una verdadera democracia sin una reforma real de este enclave autoritario, pero si eliminamos completamente la estructura corporativa, el problema resultaría más complicado y peligroso: no habría ningún mecanismo real ${ }^{3}$ —moral, político o económico-que obligue al Estado a establecer políticas redistributivas y a corregir las imperfecciones del libre mercado.

Tenemos que transitar entonces hacia un corporativismo social, de la misma manera que transitamos hacia la democracia. Esta transición podría ser lenta y larga (nuestra especialidad), con cambios graduales dentro de las esferas política y social. Un gran paso podría darse abriendo y legalizando los arreglos corporativos, que de cualquier forma siguen siendo parte de nuestra vida política.

Pero, ¿es posible introducir artificialmente esta clase de representación de intereses, corporativa?, ¿no debería ser el

3. No existen alternativas de movimientos laborales suficientemente fuertes. Las únicas dos posibilidades, el Frente Auténtico del Trabajo (FAT) y la Unión Nacional de Trabajadores (UNT) son comparativamente todavía fuerzas muy pequeñas. 
corporativismo social una disposición natural como lo argumentan algunos académicos con relación a las democracias occidentales (Suecia, Austria, Suiza, Alemania, etc.)? Mi respuesta sería: no necesariamente. En varios países europeos las alternativas corporativas fueron usadas como instrumentos eficientes para alcanzar diversos objetivos dentro del sistema democrático. Más aún, encontré casos como el español en el que, después de un viejo corporativismo autoritario y fuerte (desde Primo de Rivera en 1923), nació de los Pactos de Moncloa (1977) un corporativismo social como la iniciativa para llevar a cabo las reformas políticas y económicas necesarias en el camino hacia la democracia (Linz, 1981). Un tipo de corporativismo social puede ser encontrado en diversos lugares de Latinoamérica, como en Colombia (Urrutia, 1969), Costa Rica, Venezuela, Ecuador y Uruguay (Lanzaro, 1998). Adicionalmente, a diferencia de la gran mayoría de los corporativismos autoritarios, el corporativismo mexicano fue muy eficiente $\mathrm{y}$, al mismo tiempo, inclusivo; sus políticas redistributivas tuvieron un fuerte impacto social.

Este ensayo busca ser una propuesta de diseño institucional y organizacional. Un modelo de corporativismo social y otro de sindicalismo para México son sugeridos. Está dividido en cinco partes. En la primera, se presentan los riesgos de ingobernabilidad en los sistemas democráticos. La segunda parte es una discusión conceptual entre el corporativismo y el pluralismo, y entre el corporativismo de Estado y el social. En la tercera parte se hace un recuento de la formación del régimen político mexicano y de la creación del corporativismo de Estado. La cuarta parte contiene los modelos propuestos para el corporativismo social y el sindicalismo. En la última parte se reconoce la incertidumbre que los actores imponen en el proceso de reforma y presenta algunos de los escenarios posibles. 


\section{Democracia y gobernabilidad}

La democracia es la única forma de gobierno que, al ser inspirada por valores como los de igualdad, justicia, libertad y tolerancia, genera grandes dosis de legitimidad. Históricamente, además, los sistemas democráticos han demostrado mayor estabilidad que los regímenes autoritarios. Si la gente no está de acuerdo con sus gobernantes en un régimen autoritario, la única opción es derribar el régimen. Por el contrario, en un sistema democrático, si los ciudadanos no están satisfechos con su gobierno, las elecciones les permiten escoger otro distinto; los gobernantes cambian pero el sistema permanece.

Sin embargo, desde la otra cara de la moneda, la democracia padece en su propio seno problemas que potencialmente le restan legitimidad y ponen en riesgo su estabilidad. Siguiendo el argumento de Bobbio (1989) mencionaré los tres más importantes:

1. El "sobrecargo", es decir, la desproporción creciente entre el número de demandas de la sociedad y la capacidad de respuesta del sistema político. La democracia provoca que las demandas sean fáciles y las respuestas difíciles.

2. Una mayor "conflictualidad social"; los intereses contrapuestos son muchos; si un interés es satisfecho, otros serán afectados.

3. El poder está fragmentado y es "difuso", es decir, coexisten muchos centros de poder, que crean más problemas.

El nivel de equilibrio dinámico entre éstos problemas y la capacidad de resolución por parte del sistema definen el "grado de gobierno" ${ }^{4}$ que se ejerce en una sociedad, es decir, la gobernabilidad. A medida que las sociedades se complejizan, el equilibrio es más difícil de mantener y las

4. Antonio Camou (1995) define la gobernabilidad en la democracia como un estado, una cualidad que nos indica el grado de gobierno en esa sociedad. 
instituciones tradicionalmente democráticas, como los partidos políticos y el parlamento (en nuestro caso el Congreso) se vuelven insuficientes.

No se trata de encontrar otro sistema político que nos garantice siempre gobernabilidad, uno que por cierto no existiría. De lo que se trata es de prevenir las contradicciones que reconocemos inherentes a las instituciones democráticas e intentar perfeccionarlas. Lo que espero presentar aquí es una alternativa para tal intento. El objetivo es complementar las funciones de un sistema fuerte y competitivo de partidos y un congreso representativo con distintos modelos de representación de intereses. Pero no cualquier modelo de mediación de intereses sino uno que fomente la participación ciudadana más allá del voto y, al mismo tiempo, posibilite la formación de consensos y, por ende, haga posible la gobernabilidad.

El que los partidos políticos se conviertan en el único medio de participación y representación política podría significar la muerte de la democracia, no sólo por que son incapaces de resolver de manera eficaz todos lo problemas que la sociedad plantea, sino, principalmente, por que la democracia fue concebida desde siempre como un espacio en el cual el ciudadano goza de libertad de asociación. Tocqueville veía en esta libertad el alimento que daba vida a la democracia.

\section{Distinciones teóricas importantes}

\section{Corporativismo social y corporativismo de Estado}

Para Schmitter, el corporativismo social se encuentra en regímenes democráticos, posliberales y capitalistas. Es autónomo y producto de procesos sociales que se desarrollan fuera de la intervención del Estado. Por el contrario, podemos clasificar, por ejemplo, los regímenes fascistas en Europa, los autoritarios en Latinoamérica y algunos comu-

\section{6}


nistas en Europa del Este en la tipología de corporativismo de Estado. Por otro lado, el corporativismo social puede ser identificado en países liberales y democráticos como Suecia, Suiza o Alemania. Siguiendo con la conceptualización de Schimtter:

Corporativismo de Estado

Sistemas políticos con subunidades territoriales fuertemente ligadas a poderes burocráticos centralizados.

Elecciones inexistentes o

plebiscitarias.

Sistema de partidos políticos

dominado o monopolizado por un partido único.

Poder ejecutivo ideológicamente restrictivo.

Proceso de reclutamiento cerrado.

Subculturas políticas basadas en condiciones de clase, etnicidad, lengua o regionalismos reprimidos.

Es el resultado de una intervención positiva del Estado para implantar los canales de representación de los grupos de interés.

Régimen antiliberal, capitalista atrasado, autoritario y con un

Estado mercantilista.
Corporativismo social

Sistemas políticos con unidades territoriales relativamente autónomas y polivalentes.

Procesos electorales y sistemas de partidos políticos abiertos y competitivos.

Diversidad ideológica en las coaliciones de autoridades ejecutivas.

Autónomo y penetrativo.

Es producto de procesos sociales que se desarrollan desde fuera de la intervención del Estado (al menos en un primer momento).

Régimen posliberal, capitalista avanzado, organizado democráticamente.

\section{Corporativismo y pluralismo}

Aun con una clara diferenciación entre el corporativismo de Estado y el social, el corporativismo no es la forma de mediación de intereses más aceptada entre los académicos, ya que el paradigma democrático es dirigido por otra forma: el pluralismo. Estos dos tipos de mediación de intereses están vinculados, pero al mismo tiempo divergen en varios 
aspectos. El pluralismo es flexible y permite la creación y competencia de cualquier número de organizaciones espontáneas y representativas. Por lo contrario, el corporativismo cree en la necesidad de la configuración racional de la representación social y en la ventaja de asignar un carácter semipúblico a las organizaciones sociales (SilvaHerzog Márquez, 1997).

El corporativismo se define (Schmitter, 1992) como un sistema de representación de intereses que está configurado por un número limitado de organizaciones, las cuales están funcionalmente diferenciadas, jerárquicamente ordenadas y son reconocidas y autorizadas por el Estado. Éste les garantiza un explícito monopolio de la representación dentro de sus categorías y estas organizaciones deben otorgarle al Estado el control de la selección de sus líderes y la articulación de sus demandas y apoyos. En contraste con el corporativismo, el pluralismo está configurado por un número ilimitado de organizaciones competitivas con un número no específico de categorías. Contrariamente al corporativismo, estas organizaciones no están jerárquicamente ordenadas y no hay autorización, ni siquiera intervención del Estado.

Existe un fuerte miedo entre los defensores del pluralismo de que el corporativismo se convierta en el substituto de las instituciones tradicionales de las democracias, lo que haría a las democracias obsoletas. Sin embargo, el corporativismo ha demostrado que es un complemento (no sustituto) excelente de los partidos políticos en cuanto ayuda a perfeccionar la democracia. Los partidos políticos proponen y actúan siempre bajo la motivación de obtener más votos, lo que los convierte en una organización poco racional a largo plazo. Además, los partidos requieren mucho tiempo para la formación de acuerdos y continuamente aparecen problemas, principalmente económicos, que requieren de una rápida solución. Una alternativa es, entonces, la formación 
de consensos dentro del subsistema de las "corporaciones", lo cual es más rápido, y más racional a largo plazo.

Por otro lado, Lehbruch (1992), en sus análisis de países que optaron por alguna forma de democracia corporativa, encontró que en la mayoría de los casos se buscó que las "corporaciones" fueran sólo un complemento para sus parlamentos. El "socialismo gremial" inglés, por ejemplo, intentaba mejorar la democracia política transformándola en una democracia participativa y en Alemania los "solidaristas" católicos proponían una "cámara de corporaciones" que complementara y no sustituyera al parlamento. Así, el parlamento y las "corporaciones" se convierten en subsistemas íntimamente relacionados.

\section{El corporativismo de Estado en México}

O’Donnell (1975), tratando de hacer una diferenciación de los corporativismos de Estado latinoamericanos, distingue entre el corporativismo populista y el corporativismo en los Estados burocráticos autoritarios. Los dos son corporativismos de Estado, por lo que están organizados y son controlados por el Estado. Sin embargo, la diferencia radica en que, el primero es un sistema de inclusión social y de activación política de las mases, y el segundo, por el contrario, origina la exclusión de la clase trabajadora apoyando a las clases privilegiadas y cooptando a los líderes de las organizaciones laborales. Para O'Donnell, este último corporativismo define completamente aquellos corporativismos que surgieron en los países más avanzados de Latinoamérica, tales como México, Argentina, Chile y Uruguay.

Sin embargo, la conceptualización de O'Donnell es extremadamente simple. Lamentablemente, el corporativismo mexicano es mucho más complejo que aquel de sus vecinos. Es un inusual híbrido. Usando la distinción de O’Donnell, se podría afirmar que, por ejemplo, el corporativismo mexi- 
cano es populista en un Estado burocrático autoritario; una combinación de los dos tipos. Varios académicos estarían de acuerdo con mi afirmación, ya que han reconocido la intención de inclusión y distribución como una virtud constante del raro régimen autoritario mexicano.

Es con esta caracterización del corporativismo mexicano como un complejo híbrido, que trato de describirlo, entenderlo y explicarlo. Adicionalmente, el corporativismo no es sólo una parte complicada de la historia política de México, sino también el elemento más importante para entender nuestro sistema político. Sin traer a escena al corporativismo, setenta años del PRI en el gobierno no podrían ser explicados.

A pesar de que el origen del PRI nos remota a la creación del Partido Nacional Revolucionario (PNR) en 1929, el corporativismo nació hasta que éste se convirtió en el Partido de la Revolución Mexicana (PRM). El paso del PNR al PRM, no fue simplemente el cambio de nombre, sino el paso de una política todavía de individuos, a una esencialmente de masas, a una organización de carácter estamental, eminentemente corporativa. ${ }^{5}$ Arnaldo Córdova (1986: 11, 17 y 18) confirma esta aseveración cuando escribe: "El PNR era un partido de grupos y de individuos que hacía la también clásica política de ciudadanos, dirigida a convencer a los individuos y no a las masas [...] la lucha interna del PNR era también una lucha esencialmente individualista”. En cambio, el PRM:

5. Esta transformación se vislumbra notablemente en el discurso de campaña que dio Lázaro Cárdenas en abril de 1934: "Es necesario —afirmaba- que los pueblos se organicen, para que las organizaciones sean el más fuerte sostén de sus propios intereses. Existe en toda la nación un profundo deseo de que el pueblo trabaje, de que el país progrese y de que se mejoren moral y económicamente las masas obreras y campesinas de la República, pero para esto, para cualquiera otra tendencia que quisiera el pueblo ver realizada, se hace necesario que se organice, porque toda idea impulsada aisladamente hace nulos sus esfuerzos... En esta etapa de nuestra historia, el individuo, entidad aislada, energía mezquina y dispersa, estorba. Ha llegado la hora del Derecho Social, de la lucha de clases, pero de clases organizadas", El Nacional, 18 de abril de 1934, citado en Arnaldo Córdova (1986). 
nacía como partido de organizaciones de masas, al que estas mismas organizaciones de masas daban vida y de las cuales debía ser, a la vez, un coordinador, un servidor y la expresión de su unidad política en torno al programa de la Revolución.

De esta manera, dos momentos en el proceso de "la institucionalización de la Revolución" aparecen: el momento pluralista que va de 1917 a 1928, con momentos clímax en 1917 y 1920, la creación de la Constitución y el triunfo de Obregón sobre Villa respectivamente, y el momento de la creación del corporativismo que va de 1935 a 1938, periodo que corresponde a la presidencia de Lázaro Cárdenas. ${ }^{6}$ De hecho, los historiadores están de acuerdo con la aseveración de que el presidente Lázaro Cárdenas es el verdadero creador de este poderoso instrumento político; coinciden en que "el orden social es la herencia de Obregón. Las instituciones políticas son la herencia de Calles. El Estado hegemónico es herencia de Cárdenas" (Camacho Solís, 1980: 29).

Mas aún, concuerdan en que, aunque el corporativismo se convirtió con el tiempo en un instrumento presidencial para obtener y mantener el poder y en una forma de organización para subordinar a la clase trabajadora, la idea de Cárdenas de la estructura corporativa en el PRM no fue ésa. Lo que Cárdenas quería era reforzar el poder del Estado para proteger mejor los intereses de los trabajadores y campesinos y obtener estabilidad económica y política. Pero fue a causa de los presidentes que gobernaron después de él y que no compartieron el compromiso de Cárdenas con el bienestar social de los más pobres, que esta estructura acabó

6. Estos periodos difieren de aquellos presentados por Camacho Solís (1980). Primero, él considera dos momentos, pero los llama "semipluralista" y "semicorporativo", en su objetivo, probablemente, de ser moderado. Coincido con él en los años que forman el segundo momento (1935-1938), pero creo que el primer momento empezó mucho antes de lo que él considera (1920). Encuentro en la Constitución de 1917 el acuerdo político e ideológico entre las fuerzas revolucionarias y sociales y las bases políticas del Estado mexicano. Ésta fue la primera institución de la Revolución, la pluralidad institucionalizada. 
apoyando a los más ricos (Ai Camp, 1995). Sin embargo no todo resultó tan mal. El objetivo de estabilidad se cumplió. Un logro que nos lleva a reconocer en el Presidente Cárdenas "al estadista más hábil e inteligente de la época posrevolucionaria” (Córdova, 1972: 44).

La estabilidad del régimen político mexicano se basó en su virtud camaleónica. La idea era responder a tantos intereses como fuera posible, a los intereses de los trabajadores y a los intereses de los capitalistas. Las instituciones políticas fueron diseñadas para soportar esta capacidad de adaptarse a los dinámicos y cambiables intereses sociales, políticos y económicos. En este contexto, el corporativismo fue la alternativa institucional más adecuada: legitimidad con responsiveness prescindiendo de procesos democráticos, y estabilidad a través de la inclusión y la cooperación de clases con el menor uso de la fuerza.

Este arreglo corporativo extremadamente funcional fue apoyado por una ideología ecléctica -nacional, revolucionaria, liberal, republicana y demócrata social-y sostenido por la flexibilidad que resultaba de la creciente habilidad política de los actores. Esto último fue el aceite que permitió que el sistema trabajara,

[...] el personal político decisivo - para su ascenso y subsistencia- ha tenido que ganarse su función y utilidad. Por más que en México exista un sistema con instituciones efectivas y un presidencialismo dominante, el poder se reconstruye en cada momento y en cada momento se puede debilitar (Camacho Solís, 1980: 73).

La lección más clara sobre el funcionamiento del régimen la encontramos en la historia misma del sindicalismo. En el primer acercamiento aparece automáticamente la cara de Fidel Velázquez. ${ }^{7}$ Él, como la eterna cabeza de la Стм 
(Confederación de Trabajadores Mexicanos), ésta como la organización líder dentro del Congreso del Trabajo (ст) que, a su vez, es el intento de unificación de las organizaciones laborales.

Aunque la CTM unifica sólo a la mitad de los sindicatos del Ст, su influencia ha sido esencial en la ideología, acciones y estructura del Cт. Esta influencia de la стм sobre el Ст, como Camacho Solís señala, proviene del papel que la Стм ejerce en el PRI — y consecuentemente, en el régimen-, del reconocimiento del liderazgo de Fidel Velázquez entre los miembros del Cт y de las fuerzas que él unifica respetando la autonomía de cada organización. "La CTM es el puente institucional con el partido y en cierta medida con las autoridades políticas, como serían los secretarios de Gobernación, del Trabajo o el director del IMss" (Camacho Solís, 1980: 103). El CT es un escenario muy frágil para los movimientos laborales; es una unidad formada por un delicado equilibrio político. Sin embargo, el CT es la clave para acercarnos al pasado del movimiento laboral, para entender su presente y para configurar cualquier alternativa para el futuro.

Los treinta años de éxito (1940-1970) del modelo económico mexicano basado en la sustitución de importaciones, generó incrementos en los salarios y permitió que el movimiento laboral negociara el apoyo electoral a cambio de reformas sociales en temas como el de la salud, créditos, retiro, etc. Sin embargo, a partir de la crisis económica de 1985, las negociaciones de los movimientos laborales se hicieron más complicadas y menos ventajosas.

Por ello, durante la presidencia de Miguel de la Madrid (1982-1988) se estructuraron consensos entre las principales "corporaciones" con el fin de hacer frente al legado de 12 años de gasto deficitario y de laxismos en las políticas. El resultado de tales consensos fue el Programa Inmediato de Reordenación Económica (PIRE) para el periodo 1983-1985. $\mathrm{Su}$ objetivo era restablecer las condiciones necesarias para 
la estabilidad de los precios y de las condiciones financieras mediante una drástica corrección del desequilibrio fiscal. Además pretendía corregir las distorsiones de la acelerada inflación. Los resultados fueron: la reducción en 8.5 puntos porcentuales, con respecto al PIB, de la razón de los requerimientos de endeudamiento del sector público, la producción se contrajo fuertemente, el equilibrio externo registró un impresionante superávit (5.7\% respecto del PIB), y la tasa anual de la inflación cayó en sólo 20 puntos porcentuales.

Después, en 1987 el gobierno y los representantes del trabajo, los campesinos y las empresas, suscribieron el Pacto de Solidaridad Económica (PSE o Pacto) con le objetivo fundamental de abatir la inflación sin provocar una recesión, el Pacto se renovó en cinco ocasiones a intervalos cada vez mayores a medida que se restablecía la confianza. Sin embargo, la reanudación del crecimiento con la consolidación de la estabilidad de precios no era viable mientras México siguiera siendo un exportador neto de capitales y como consecuencia de ello requiriera mantener grandes superávit comerciales. Las transferencias estaban drenando el ahorro interno obstaculizando la inversión requerida y por ende limitando el crecimiento.

Fue a causa de esta situación que el presidente Carlos Salinas creó el Pacto Para la Estabilidad y el Crecimiento Económico (PECE) en diciembre de 1988. La meta última era reducir las transferencias netas de recursos hacia el exterior, que resultaban de la onerosa carga de la deuda externa. Este Pacto fue sustituido por el Programa de Estabilización anunciado en enero de 1995. Los arreglos corporativos fueron así exitosos en superar las crisis, pero los trabajadores terminaron siendo los que más perdían. Los presidentes Miguel de la Madrid y Salinas de Gortari llevaron a cabo reformas neoliberales que incluían, entre otras políticas, drásticas reducciones de los subsidios gubernamentales y privatizaciones de empresas paraestatales; 
reformas que dañaron el nivel de vida de los trabajadores y llevaron a los movimientos laborales a la crisis.

Corporativismo en la economía y la política mexicana hoy

El programa neoliberal no es compatible con las prácticas corporativas, por lo menos no en el apoyo a los trabajadores y en el reconocimiento de la intermediación laboral. Los capitalistas buscan avanzar en sus planes neoliberales sin discusiones ni negociaciones. La meta es exaltar la idea del individuo poniéndolo en una situación de lucha irreconciliable en contra de la concepción de clase. Lo que importa ahora es el ciudadano y no el trabajador. Por lo tanto, la intermediación es un fastidioso obstáculo. Una relación directa pero fragmentada con individuos atomizados, es la estrategia laboral neoliberal. La competencia es privilegiada en contra de la "negociación gubernamental". Sin embargo:

[...] los empujes de regulación competitiva suelen ser, por lo demás, asimétricos: no cancelan la presencia oligopólica de los grandes complejos capitalistas, pero se encargan de imponer, del lado de los trabajadores, ciertas coordenadas de individualización y tratamientos colectivos fragmentarios compartimentados, plurales, heterogéneos (Lanzaro, 1998: 47).

Las crisis políticas fueron disueltas gracias al diseño político corporativo. La crisis económica fue debilitada con arreglos corporativos. Aun con todo, el corporativismo mexicano está en crisis y se encuentra en esta situación por que se tuvieron que hacer grandes sacrificios soportados fundamentalmente por los trabajadores, como su contribución al logro de estabilidad política y económica.

El corporativismo representó una gran pérdida para el sindicalismo en el momento en que éste ayudó a crear un 
régimen hegemónico, sacrificando su autonomía e independencia y apoyó el avance del neoliberalismo, con la reducción de salarios y más desempleo.

Para los trabajadores, el neoliberalismo implantado en México [...] ha significado una fuerte reducción de los salarios reales y múltiples despidos, la desarticulación de una vieja clase trabajadora de la Revolución mexicana, el surgimiento de una nueva clase trabajadora de "maquila" (De la Garza, 2000).

El sindicalismo perdió legitimidad social y el apoyo de los trabajadores.

Se puede fácilmente elaborar una lista de las características (la mayoría negativas, por cierto) del sindicalismo en México; entre ellas, la ineficiencia, burocracia, corrupción, patrimonialismo, incompetencia y clientelismo. Frecuentemente es caracterizado como "corporativismo hormiga", el cual está relacionado con la permisividad, llegadas tarde al trabajo, promociones fraudulentas, distribución de vacaciones con base en las preferencias del líder sindical, tráfico de influencias (De la Garza, 1993). Todas estas características pueden resumirse en lo siguiente: falta de democracia y falta de productividad. Sin lugar a dudas, México ha cambiado y ha cambiado con el PRI, sin el PRI y a pesar del PRI. Esto, ni remotamente hubiera podido ser afirmado hace algunos años. Desde 1972, cuando describía Daniel Cosío Villegas, con maestría valga decirlo, el sistema político mexicano, lo hacía siempre a partir de las dos piezas que él consideraba como centrales: la presidencia de la República y el partido oficial. Afirmaba que la democracia en México sólo podría ser posible mediante la transformación de estos dos poderosos sustentos del autoritarismo mexicano. Era tal la preponderancia de estos monstruos que ni en sus sueños democráticos, la oposición o la opinión pública tenían esperanzas en su realización. 
Aún una hora antes de las elecciones de 2000, el PRI continuaba utilizando como mecanismo de control el corporativismo de Estado, sus líderes eran designados sin el menor ápice democrático, las decisiones eran tomadas por una élite centralista, los métodos antiguos de cooptación se seguían practicando, y su subordinación hacia la figura presidencial permanecía. Pero por primera vez, el presidente de la República fue de un partido distinto al que había sido el "hegemónico". El Partido Revolucionario Institucional no cambió y aun así, la transición en México experimentó, a partir de un proceso de liberalización casi eterno, sus “elecciones fundacionales". Encontró en las elecciones intermedias de 1997 lo que parecía ser la excepción de un proceso limpio y muy competitivo, y en las de 2000, la normalidad democrática.

El régimen autoritario mexicano, al verse ilegítimo, y ante la imposibilidad evidente de escoger cualquier otra vía, elige la democracia como fuente de estabilidad y renovada legitimidad. Esta elección es siempre estratégica y calculada, por lo que la democracia siempre es limitada. Elige el camino de la liberalización con el fin de mantener controlado el cambio. Entre más libertades y derechos otorgaba a la aposición la posibilidad de cerrar de nuevo el sistema, era más costoso que continuar en la senda de la apertura. El régimen nunca imaginó perder el poder a través de este proceso; de hecho, había decidido transitar por esa vía con el único fin de conservarlo. "En situaciones de deterioro político, una liberalización puede contribuir al reequilibrio del régimen, pero también constituirse en un factor disfuncional de ruptura y cambio" (Cansino, 1995: 162). Esto último fue al fin lo que sucedió. Sin embargo, los avances son fundamentalmente de administración electoral y las grandes tareas y reformas de Estado quedan pendientes.

Lo que es claro es que el corporativismo de Estado mexicano está en crisis. Las circunstancias cambiaron pero la 
estructura no lo hizo. El corporativismo de Estado fue el diseño institucional ideal para el régimen autoritario y para una economía de sustitución de importaciones. México busca ser ahora democrático y neoliberal. Sin embargo, parece que a la mesa le falta una pata: el trabajador no ha sido considerado aún. Está latente la inestabilidad.

\section{Hacia un modelo de corporativismo social}

Al fin del siglo del corporativismo, con los altibajos del caso y en un plano de coloraciones muy variadas, atravesamos pues por una estancia en la que pueden estar esbozándose, sin aspaviento, las siluetas de un nuevo ciclo corporativo. No hay que asombrarse, porque ello no haría sino marcar el relevo de un insumo corriente en los sistemas

modernos

(Lanzaro, 1998: 57).

Cualquier propuesta de reforma de una estructura corporativa debe contener elementos de diseño institucional, organizacional y constitucional. En este ensayo se presentarán propuestas de diseño institucional y organizacional. El diseño constitucional será parte de otro análisis. El objetivo es generar un modelo en el que la actual estructura corporativa sea transformada para hacerla compatible con la democracia y genere las dosis necesarias de gobernabilidad. Más aún, puesto que afirmo que un corporativismo social no puede existir sin un modelo específico de sindicalismo, la reforma de éste último se convierte, entonces, en una tarea también indispensable; sobretodo si consideramos que la energía para el proceso de trasformación tiene que venir de "abajo" para que el corporativismo sea verdaderamente social.

Los asuntos públicos deben ser decididos por el pueblo. El espíritu del interés general debe ser la motivación y marca de nacimiento de cualquier decisión y acción política. Es aquí donde un problema típico aparece: ¿cómo hacer a 
Democracia en México: transición hacia un corporativismo social

un gobierno representativo y al mismo tiempo eficiente? $\mathrm{O}$ en otras palabras, ¿cómo hacer a una democracia gobernable?

La historia nos ha mostrado la imposibilidad de crear una estructura de representación en la que todos los intereses estén funcionalmente representados. Por ello, al no haber ninguna otra alternativa, me confirmo en la institución que nuestra idea de democracia representativa ha creado: el Congreso; sus diputados y senadores como los representantes del pueblo, y sus decisiones como la expresión de la voluntad del pueblo. Sin embargo, también afirmo que el Congreso es una institución necesaria pero no suficiente para la representación.

El presente modelo considera el arreglo corporativo en su mínima expresión, esto es, el arreglo tripartita. La estructura corporativa, por lo tanto, se presenta como el espacio en donde los intereses del gobierno - representado por el secretario de Trabajo - de los capitalistas - representados por las organizaciones patronales-, y de los trabajadores -representados por los sindicatos-, que entran en pugna y donde las decisiones se toman por consenso y negociación.

Diseño institucional: la compatibilidad posible entre el corporativismo y la democracia

El diseño institucional es totalmente pertinente si lo que se busca es que: 1. La institución propuesta esté adherida a un principio normativo y a un conjunto de valores. 2. La institución sea compatible con todo el entramado institucional. En otras palabras, el diseño institucional nos permite considerar a la institución como una pieza más del rompecabezas, como un bloque en la ingeniería constitucional. En el México actual, cualquier institución alternativa debe estar de acuerdo con la democracia y sus valores, por lo que el modelo corporativo que propongo debe ser compatible con 
la democracia y, al mismo tiempo, debe trabajar junto con las otras instituciones democráticas, tales como el Congreso y los partidos políticos.

Ahora sabemos, gracias a un importante número de estudios de caso, que el corporativismo - específicamente, el corporativismo social - ha demostrado ser compatible con la democracia. Pero, ¿cuáles son las condiciones necesarias para que el corporativismo social funcione? ¿Cuáles son sus características esenciales? ¿Qué hicieron otros países para que el corporativismo fuera compatible con la democracia? y, finalmente, ¿cómo vamos a trasformar nuestro corporativismo de Estado en un corporativismo social?

De la conceptualización que hace Schmitter del corporativismo social a partir de la experiencia de los países que cuentan con este modelo corporativo, podemos inferir las condiciones necesarias para que éste funcione. En el siguiente cuadro se muestran estas condiciones y se contrastan con la situación actual del país.

Las características generales que Schmitter reconoce en el modelo corporativo de representación de intereses, en contraste con el modelo pluralista, están presentes en el modelo corporativo mexicano: un número limitado de organizaciones que están funcionalmente diferenciadas, jerárquicamente ordenadas y reconocidas y autorizadas por el Estado. Éste les otorga el monopolio explícito de la representación, con la condición de permitir cierto control en el proceso de selección de sus líderes y en la articulación de sus demandas y apoyos.

De los países que han adoptado un modelo de corporativismo social, Suecia es el caso que mejor combina la estructura corporativa con otras instituciones democráticas, como el Parlamento (Martín, 1975). En términos de diseño institucional, por lo tanto, este caso resulta extremadamente interesante para lo que se está proponiendo para México. En este sentido, encontré muy convincentes los principios de diseño institucional que Charles Anderson (1992) presenta, 
Condiciones en países con corporativismo social

Económicas: dirección capitalista de la economía.

Políticas:

1. Sistema democrático: procesos electorales y sistema de partidos abierto y competitivo. 2. Estructura federalista: unidades territoriales autónomas y polivalentes.

Características de las coaliciones gubernamentales: diversidad ideológica en las coaliciones.

Condición básica para la creación de (o transformación a) un modelo de corporativismo social: el proceso debe ser autónomo y producto de movimientos sociales que se desarrollan fuera de la intervención del Estado.

\section{Condiciones en México}

En 1980, México transformó su economía centrada en la sustitución de importaciones en una economía neoliberal, y todo parece indicar que este modelo permanecerá.

1. La elecciones de 1994 fueron calificadas por primera vez como limpias, y el sistema de partidos era ya abierto y con cierto grado de competencia (aunque ningún partido tenía oportunidades reales de ganar). En las elecciones de 1997 la transformación democrática avanzó. Las del 2000 fueron las "elecciones fundacionales".

2. México es constitucionalmente un país federalista, pero en la práctica ha sido centralista. Sin embargo, algunas prácticas federalistas están apareciendo de manera más constante, por lo menos en el plano electoral. Partidos diferentes están gobernando diferentes estados.

Si consideramos el modelo tripartita de negociación como el modelo corporativo por excelencia, las posiciones ideológicas no fueron distintas. Los sindicatos compartieron (por fuerza o por convicción) los mismos ideales del partido oficial y, consecuentemente, los ideales del régimen. Por otro lado, con la reforma neoliberal parece no haber diferencia entre los intereses del gobierno y los de los capitalistas. La presidencia de Fox muestra claramente las semejanzas entre los intereses del gobierno y los de los patrones.

México todavía no experimenta este proceso. De hecho, es parte de la propuesta. A causa de que el corporativismo en México fue de Estado, el proceso de creación fue dirigido y controlado por éste. El objetivo es un proceso de transformación a través de las renovadas energías del sindicalismo reformado. 
basado en el corporativismo sueco, como el medio para hacer al corporativismo compatible con la democracia. Anderson afirma que en un orden democrático, la representación de intereses es legítima sólo si contribuye a lograr las aspiraciones públicas estipuladas. En este sentido propone dos principios:

1. El criterio de representación de intereses (quién debe estar representado) tiene que ser incluido en una norma substantiva de formación de políticas.

2. Las decisiones tomadas por las estructuras de representación de intereses no se vuelven legítimas por el principio de representación en los que la toma de decisiones se basó, sino por la compatibilidad de estas decisiones con el criterio sustantivo de acción política.

El Congreso se convierte así en la única institución democrática de representación política. Es en el seno del Congreso donde las aspiraciones públicas se definen, y cualquier arreglo corporativo debe responder a esas aspiraciones. De esta manera, el corporativismo puede responder a sus pragmáticos y funcionales propósitos siendo compatible con la democracia; porque sólo dentro de una estructura democrática las corporaciones pueden negociar.

El modelo corporativo es, así, congruente con los principios esenciales del diseño democrático porque, como establece Anderson:

[...] la representación de los grupos de interés ayuda a alcanzar un interés público ya estipulado. Es imparcial porque existe una regla racional defendible para el reconocimiento o desconocimiento de participantes específicos, y es complementario al consenso popular en la medida en que las aspiraciones públicas son definidas a través de medios parlamentarios (Anderson, 1972: 268).

Es de esta forma que la gobernabilidad puede lograrse sin sacrificar la democracia. 
Recapitulando, el modelo que propongo para México es el corporativismo social definido esencialmente por pactos tripartitas - gobierno, patrones y trabajadores-y en el que las negociaciones y consensos se hacen siempre dentro de una estructura democrática definida por el Congreso. Esta estructura debe incluir el criterio con el que se reconocerá como necesaria cierta representación de intereses y con el que se definirán las aspiraciones públicas — "el criterio sustantivo para la acción política”- El arreglo corporativo asistirá al sistema político a lograr las metas que la sociedad definió a través de las instituciones democráticas tradicionales. Los riesgos de ingobernabilidad o en otras palabras los riesgos de "sobrecargo", "conflictualidad social" y de fragmentación del poder serán disminuidos en la medida en que la estructura corporativa ayude al sistema político a: 1. Limitar el número de demandas sociales organizándolas y canalizándolas. 2 . Responder a tales demandas. 3 . Reducir el número de intereses contradictorios organizándolos racionalmente. 4. Satisfacer mejor y más eficientemente los intereses a través de negociación y el consenso. En pocas palabras, ayudará a reducir complejidad.

Adicionalmente, la virtud más importante de este modelo corporativo será la flexibilidad. Por lo tanto, una combinación de "macro" y "mesocorporativismo" se considera. El criterio por el que el nivel de un arreglo corporativo se decide puede ser parte del primer principio que Anderson nos presenta, “quien debe estar representado". Sin embargo, puesto que este elemento es de especial importancia, se requiere tratarlo de manera más específica.

Tradicionalmente, las estructuras corporativas han sido identificadas con negociaciones en el nivel macro. Sin embargo, experiencias recientes muestran que los arreglos "mesocorporativos" son igualmente, y en algunos casos más, útiles que los "macrocorporativos" y son, sobre todo, más flexibles. Como establece Lanzaro: 
[...] la continuidad [del corporativismo] se asienta a la vez en otras ediciones de relevo —el "mesocorporativismo", el corporativismo "sectorial" o "local", el "microcorporativismo"- que delinean un modelo con temperamento "liberal", de menor escala y relativamente descentralizado, más abierto e informal, más especializado, a veces pluralista, sin descartar monopolios de un estilo "contractual" o "voluntario", comparable con el que predominó antes de 1930, pero con un toque netamente actual, que se ajusta a las evoluciones finiseculares (1998: 14).

Sin duda, el asunto a discutir indicará el nivel de la negociación. Por ejemplo, asuntos más generales como el salario mínimo, las condiciones de trabajo, las políticas de productividad y los niveles de inflación y desempleo deben ser discutidos en el nivel macro. Por el contrario, asuntos más regionales y específicos, tales como los problemas originados por las maquiladoras, deben ser negociados en el mesonivel. De esta manera, la estructura corporativa será no solo flexible sino también más eficiente. Además, esta combinación de "macro" y "mesocorporativismo" permitirá la competencia dentro del monopolio de la representación a través de la división de tareas y poder de decisión.

Un modelo de corporativismo social no puede considerarse terminado sin la consideración de un modelo de sindicalismo. Es en este punto donde la transformación del corporativismo de Estado mexicano en uno social debe empezar. Sólo con un sindicalismo unificado, democrático y productivo, México puede alcanzar las dos condiciones necesarias para una estructura corporativa social que le hacen falta: "la diversidad ideológica en las coaliciones gubernamentales" y la posibilidad de que el modelo de corporativismo social sea "autónomo y el producto de procesos sociales que se desarrollan fuera de la intervención del Estado".

Se ha señalado ya en este ensayo que México cambió política, social y económicamente y que, sin embargo, el 
sindicalismo no ha cambiado. El corporativismo mexicano no puede transformarse aún a causa de ese enclave del corporativismo de Estado. La característica autoritaria del sindicalismo mexicano lo ha llevado a su propia crisis. Si éste va a transformarse, es ahora el mejor momento de hacerlo. Las crisis proporcionan oportunidades para el cambio.

Diseño organizacional: un nuevo sindicalismo

como condición indispensable

Un modelo de sindicalismo compatible con el corporativismo social en México tiene que diseñarse en torno a tres principios básicos: unidad, democracia y productividad. En esta parte sólo mencionaré los elementos que reconozco como indispensables en el diseño de un nuevo tipo de sindicalismo.

Ya se ha establecido en páginas previas que la estrategia neoliberal en contra del sindicalismo ha sido promover la confrontación entre los trabajadores para crear divisiones y para fragmentar su fuerza. En pocas palabras, la táctica neoliberal ha sido debilitar política y socialmente al trabajador con el fin de mantener bajos salarios y pobres condiciones laborales. En este contexto, la estrategia de unificar a los sindicatos se hace crucial. Una unidad funcional en forma de frente o confederación es la estructura que mejor puede adaptarse al caso mexicano. Por lo que el cT y la UNT se convierten en las estructuras clave en la reforma del sindicalismo. La idea será usar una de estas estructuras ${ }^{8}$ como el objeto de la reforma. Esta estructura debe estar federalizada con entes regionales y con un comité directivo general plural integrado por comisiones permanentes.

8. No estoy aún segura cuál podría ser mejor. Por un lado, el CT tiene tradición, historia, experiencia, es más poderosa, está integrada por más sindicatos, etc., pero, consecuentemente, tiene poderosas inercias antidemocráticas. Por otro lado, la UNT ha demostrado ser una alternativa más democrática, pero su fuerza es muy pequeña y su capacidad de negociación muy limitada. 
Adicional a la estrategia de unificación, es elemental la democracia interna de la estructura sindicalista. Sin prácticas y procesos democráticos internos, el monopolio de la representación otorgada por el Estado sería totalmente ilegítimo. Es simplemente imposible que el corporativismo social sea compatible con la democracia si la organización laboral no es democrática. Los líderes deben ser electos y las decisiones deben ser tomadas a través de procesos democráticos. La disciplina, elemento indispensable para que exista una estructura corporativa, solo es justificada cuando las decisiones son el resultado de discusiones, debates y consensos dentro de la organización.

Finalmente, pero no menos importante, el principio de productividad debe infiltrarse no sólo en la estructura burocrática de la organización sino también en la cultura laboral. Hernández y López, por ejemplo, afirman que:

[la] productividad [social] es indispensable porque, al final de cuentas y sin mayores complicaciones, los problemas económicos del modelo anterior fueron causados básicamente por la debilidad productiva, que se tradujo en fenómenos como dependencia, déficit comercial, endeudamiento externo, pérdida de competitividad, pérdida de empleos y lo que de todo esto resulta, invariablemente (1993: 138).

Sin embargo, el asunto más importante continúa siendo el problema de la voluntad: ¿trabajarían los actores políticos por una transición hacia un corporativismo social? La esperanza descansa en la trasformación del sindicalismo en uno unificado, democrático y productivo. Pero entonces la pregunta sería, ¿cuáles son las posibilidades de cambio en el sindicalismo mexicano? 


\section{La incertidumbre en el proceso de transformación,} como conclusión

\footnotetext{
Incluso de darse una recuperación económica sostenida en los próximos años, los trabajadores alcanzarán beneficios limitados de ello, si no se da un fortalecimiento del sindicalismo y de la negociación colectiva, extendida a la negociación del cambio social mismo. De aquí la importancia de definir y apresurar este proceso, y de ahi también los intereses por posponerlo o por limitarlo.

(Hernández y López, 1993: 126.)
}

Es muy difícil elucidar qué es lo que está sucediendo en este periodo de múltiples transformaciones. Todo es muy confuso, estamos muy cerca de los eventos. Para tratar de entender se hace necesario, entonces, distinguir posibles escenarios por medio de una lectura de las posiciones actuales de los actores políticos principales. Primero, del lado de las organizaciones labores se pueden percibir tres posiciones: la posición de la vieja hegemonía sindical (Стм), la posición de la UNT y la posición de la Coordinadora Primero de Mayo. Segundo, en el lado del gobierno: las posiciones del presidente Fox y del secretario de Trabajo, junto con la del Partido Acción Nacional. Tercero, la posición de los partidos de oposición, del Partido Revolucionario Institucional y del Partido de la Revolución Democrática. Cuarto, la posición de los patrones.

1. Las organizaciones laborales

a) La CTM tiene cuatro opciones de acción: liberarse del PRI pero continuar con sus relaciones de dependencia con el nuevo gobierno, continuar siendo parte del PRI, aliarse con la UNT o transformarse en una organización independiente y democrática. Estas opciones están ordenadas con base en el grado de posibilidad de que suceda. En otras palabras, la primera opción es más 
probable que suceda que la segunda, la segunda más que la tercera, etcétera.

b) La UNT fue creada en 1997 por todas esas uniones que no eran parte del Ст. ${ }^{9}$ Ésta tiene la alternativa de continuar siendo una fuerza prodemocrática dentro del sindicalismo y defender la idea de libertad sindical en contra del modelo corporativo o tomar el lugar del CT y la CTM en la relación con el gobierno, sacando ventaja de la pésima imagen de estas organizaciones.

c) La Coordinadora Primero de Mayo apareció en el escenario mexicano en 1996 como una respuesta de la izquierda en contra de las políticas laborales promovidas por los gobiernos neoliberales y apoyadas por la vieja estructura corporativa. Sin embargo, sus esfuerzos no tuvieron resultados ${ }^{10}$ porque, por un lado, estaba basada sólo en el resentimiento y en posiciones radicales ${ }^{11} \mathrm{y}$, por otro, estaba internamente dividida.

2. El gobierno.

a) El presidente Fox tiene pocas alternativas. Por un lado, puede continuar negociando con el ст y con la CTM al estilo antiguo y, por otro, puede ser congruente con sus propuestas de campaña y, por lo tanto, erradicar la estructura corporativa y proclamar la libertad sindical.

b) El secretario de Trabajo ${ }^{12}$ y el PAN pueden continuar apoyando al poder capitalista en contra de los intereses de los trabajadores o apoyar al presidente Fox en lo que decida.

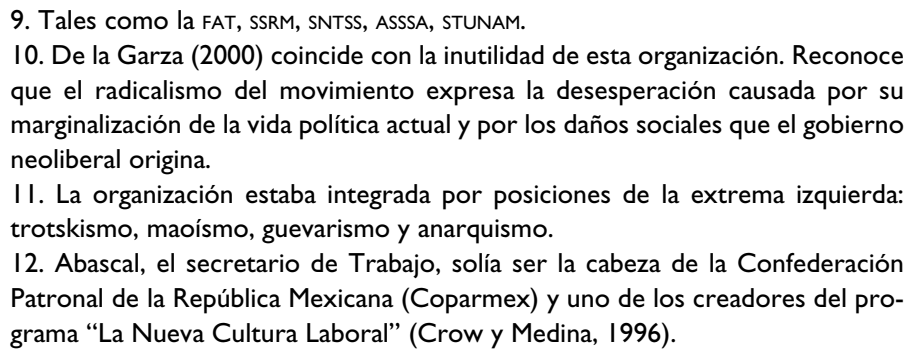
que el radicalismo del movimiento expresa la desesperación causada por su marginalización de la vida política actual y por los daños sociales que el gobierno neoliberal origina.

II. La organización estaba integrada por posiciones de la extrema izquierda: trotskismo, maoísmo, guevarismo y anarquismo.

12. Abascal, el secretario de Trabajo, solía ser la cabeza de la Confederación Patronal de la República Mexicana (Coparmex) y uno de los creadores del programa "La Nueva Cultura Laboral" (Crow y Medina, 1996). 
3. Partidos de oposición.

c) Parece que el PRI está ocupando todo su tiempo y energías tratando de resolver las divisiones internas, pero solo tiene una alternativa pragmática: reconquistar el apoyo de los trabajadores.

d) El PRD no envía claros mensajes sobre su posición actual al respecto. Solía jugar con los sindicatos radicales como la Coordinadora Primero de Mayo. Tradicionalmente, este partido ha criticado fuertemente tanto la estructura corporativa como las políticas neoliberales.

e) Los empresarios tienen dos posiciones: criticar la estructura corporativa y promover en su lugar la creación de los "sindicatos blancos", ${ }^{13}$ una posición antisindical o luchar por que la situación siga igual, sin cambio.

El presidente Fox tiene la típica posición contradictoria entre lo que dice y lo que hace. Desde su campaña electoral, hasta el momento, ha declarado que promoverá la aniquilación del corporativismo. Sin embargo, ha sido muy pragmático. Contradiciendo lo que dice en la televisión o en los eventos masivos, ha declarado en varias reuniones sindicales que seguirá promoviendo la conformación de arreglos tripartitas ${ }^{14}$. Existe un importante número de señales que muestran que Fox preservará la vieja estructura corporativa. Más aún, la creación del Consejo para el Diálogo entre los sectores productivos en su primer año como Presidente es evidencia de su preferencia por las estructuras corporativas (La Botz, 2001). El Consejo es parte del programa laboral de Zedillo llamado "La Nueva Cultura

13. Los "sindicatos blancos" son organizados por una compañía o planta y sus líderes responden a los intereses del patrón. Por lo tanto, estos sindicatos están completamente fragmentados y no responden a los intereses de los trabajadores. 14. Al respecto, véase "Fox praises стм Old Guard", en Mexican Labor News and Analysis, vol. vı, núm. 3, marzo, 200 I, Pp. I-2, y “Fox praises CтM leader Rodríguez Alcaine”, en Mexican Labor News and Análisis, vol. V, núm. 8, noviembre 2000, pp. I-2. 
Laboral". Desde sus inicios, el programa fue criticado por ser una evidente continuación del viejo estilo corporativo, creado con la intención de controlar las insatisfacciones de los trabajadores. Así, el Consejo es también una organización tripartita que aspira a lograr acuerdos en asuntos de empelo, condiciones laborales y productividad.

Existe, además, otro elemento que contribuye a la personalidad múltiple en la conducta de Fox: su partido, el PAN. Es necesario afirmar que existe una marcada diferencia entre la posiciones de ese partido como gobierno y como oposición. Tradicionalmente, el pan ha tenido un sentimiento antisindicalista. Esto es perfectamente lógico si consideramos que el partido fue creado y esta mayoramente compuesto por miembros de derecha, capitalistas y conservadores. Por un lado, el partido representa sus propios intereses, los intereses capitalistas y por el otro, en declaración de principios la conciencia de clase es negada; no hay una clase trabajadora sino sólo "personas humanas". Es así que, frecuentemente, prefieren seguir sus intereses en lugar de sus principios normativos, y sin respeto a la "persona humana", promueven la creación de "sindicatos blancos" o peor, la desaparición de los sindicatos. La situación cambia completamente cuando gobiernan, el elemento más molesto de pronto se convierte en el instrumento más útil. De esta manera, la estructura corporativa es explotada en busca sus propios intereses. El caso de Baja California es un ejemplo de lo anterior. Es obvio que es cuestión de tiempo para que Fox clarifique su posición, por lo pronto está explotando esta ambivalencia (La Botz, 2000).

La opción de cambio está más cerca de los partidos de oposición, ya que tienen la ventaja de no ser gobierno. Esta situación les da libertad de acción al tener menos responsabilidad. El PRI debe saber que el viejo sindicalismo "revolucionario" no puede sostenerse ya, y que continuar con sus oscuras relaciones con los líderes de la CTM disminuirá aún 
más su ya reducida legitimidad. El PRD debe saber también que el extremismo y el radicalismo no tienen ninguna posibilidad real de poder y apoyo de la gente. La arena política esta dominada por posiciones moderadas: de centro-derecha o de centro-izquierda.

Los partidos de oposición deben decidir estrategias entre los niveles macro y meso. En el nivel macro pueden presionar al presidente para que apoye la organización independiente UNT y que ayude a reformar el CT. En el nivel meso pueden negociar con cada uno de los sindicatos y, dependiendo del problema y asunto a resolver, usar su estructura territorial. Tienen que decidir por el modelo corporativo social o el modelo pluralista.

Sin embargo, la pregunta sobre la voluntad política para el cambio queda abierta. Cualquier respuesta a esta pregunta sería una predicción, habilidad que desafortunadamente no tengo. Lo importante es saber que México finalmente logró la normalidad democrática. Los ciudadanos tienen grandes expectativas en la democracia. Estas expectativas nacieron y renacieron en julio del 2000. Fox prometió demasiado. La gente quiere ser realmente representada y eficientemente administrada. Si el respeto a la voluntad popular impone pluralidad y esta última resulta en desestabilización, ineficiencia e ingobernabilidad, la democracia será inútil y la población sentirá nostalgia ("los tiempos pasados fueron mejores") y demandará soluciones autoritarias: "[quien] le ofrezca tranquilidad para sus hijos será recibido por [la población] como el salvador. No derramaría una lágrima si el pago por la paz es el desplome de los ritos democráticos" (Silva-Herzog, 1999: 148). El riesgo de retorno a nuestro pasado autoritario está presente. 
Bibliografía

Ai Camp, Roderic, La política en México, México, Siglo XXI Editores, 1995.

Anderson, Charles W., "Diseño político y representación de intereses", en Schmitter y Lehnbruch (eds.), Neocorporativismo I: Más allá del Estado y el mercado, Alianza Editorial, 1992.

Bobbio, Norberto, Liberalismo y democracia. México, Fondo de Cultura Económica, 1989.

Camacho, Manuel, La clase obrera en la historia de México. México, Instituto de Investigaciones Sociales, UNAM, 1980.

Camou, Antonio, "Gobernabilidad y democracia", en Cuadernos de divulgación de la Cultura Democrática, núm. 6. México: Instituto Federal Electoral, 1995.

Cansino, César, Construir la democracia. Límites y perspectivas de la transición en México. México, CIDE/Porrúa, 1995.

Córdova, Arnaldo, La política de masas y el futuro de la izquierda en México. México, Serie Popular, núm. 72, 1986.

Cosío Villegas, Daniel, El sistema político mexicano. Las posibilidades de cambio. México, Joaquín Mortiz, 1982.

Crow, David y Javier Medina, "New Labor Culture?", documento electrónico, http://flag.blackened.net/ revolt/mexico/reports/sudeal.html, 1996, consultado en mayo 6, 2002.

Garza Toledo, Enrique de la, El sindicalismo mexicano frente a la transición política, Buenos Aires, Biblioteca VirtualClacso, 2000.

- Reestructuración productiva, contratación colectiva y crisis del sindicalismo en México, México, UAM-Iztapalapa, 1993.

Hernández, Francisco y María López, El sindicalismo en la reforma del Estado, México, Fondo de Cultura Económica, 1993. 
Democracia en México: transición hacia un corporativismo social

La Botz, Dan () "Labor after the PRI. Will Fox Ride Roughshod Over Mexican Workers?", en The Multinational Monitor, marzo. documento electrónico document, http: //www.thirdworldtraveler.com/Mexico/Labor_After_ PRI.html, 200I, consultado en mayo I2, 2002.

Lanzaro, Jorge, El fin del siglo del corporativismo, Caracas, Nueva Sociedad, 1998.

Linz, Juan () "A Century of Politics and Interests in Spain”, en Berger (ed.), Organizing Interest in Western Europe: Pluralism, Corporativism and the Transformation of Politics, Nueva York, Cambridge University Press, 198I.

Martín, A., "Is Democratic Control of Capitalist Economies Possible?", en Lindberg (ed.), Stress and Contradiction in Modern Capitalism. Lexington, Lexington Books, 1975.

O'Donnell, Guillermo, Acerca del corporativismo y la cuestión de Estado, Buenos Aires, Cedes, 1975.

Schmitter, Philippe, Teoría del neocorporatismo, Guadalajara, (col. Laberinto de Cristal), UdeG, 1992.

Silva-Herzog Márquez, Jesús, "Esferas de la democracia", en Cuadernos de Divulgación de la Cultura Democrática, núm. 9. México: IFE, 1997.

_- El antiguo régimen y la transición en México. México, Planeta-Joaquín Mortiz, 1999.

Trejo, Raúl, "Cronología de la insurgencia sindical de México I 97I-1978”, en Serie de Materiales Estudio, núm. I, México, Facultad de Ciencias Políticas y Sociales, UnAM, 1979.

Urrutia, Miguel, Development of the Colombian Labor Movement, New Heaven, Yale University, 1969. 